\title{
Phylogenetic, antigenic and biological characterization of pigeon paramyxovirus type 1 circulating in China
}

Xusheng Qiu', Chunchun Meng ${ }^{1}$, Yuan Zhan ${ }^{1}$, Shengqing Yư ${ }^{1}$, Shichao $\mathrm{Li}^{1}$, Tingting Ren ${ }^{1}$, Weifeng Yuan ${ }^{1}$, Shuqin Xu' ${ }^{1}$ Yingjie Sun ${ }^{1}$, Lei Tan ${ }^{1}$, Cuiping Song ${ }^{1}$, Ying Liao ${ }^{1}$, Zhuang Ding ${ }^{4}$, Xiufan Liu ${ }^{2,3}$ and Chan Ding ${ }^{1,3^{*}}$ (D)

\begin{abstract}
Background: For many years, ND has been one of the most important infectious pigeon diseases in China. In recent years, a high mortality has been observed in ND-infected pigeons in China. Mortality is from 40\% to $80 \%$ or $100 \%$ in some cases.

Methods: The full-length genomes of four pigeon paramyxovirus type 1 (PPMV-1) strains, which were isolated from infected pigeons in China in 2012 and 2013, were sequenced and analyzed to determine the phylogenetic characteristics of PPMV-1 circulating in pigeons of China in recent years. Furthermore, cross hemagglutination inhibition and cross virus neutralization assays, as well as animal experiments were conducted to determine the antigenicity and pathogenicity of those viruses. Proteolytic cleavage sites (residues 112-117) of the F proteins were identified as the typical virulence motif, ${ }^{112}$ RRQKR $\downarrow F^{117}$ for all four PPMV-1 strains investigated.

Results: Phylogenetic analysis based on sequences of complete genomes and F gene revealed that the four PPMV-1 isolates and most of recent isolates in China were highly homologous to European isolates from 1998 to 2011. All those isolates were clustered in one clade of genotype VI NDV, termed as subgroup 4bii f. The $R$ value was calculated based on cross hemagglutination inhibition and cross virus neutralization results, and confirmed antigenic difference of the PPMV-1 strains isolated in 2013 from the LaSota vaccine strain. Several mutations were identified in the surface glycoproteins $\mathrm{F}$ and $\mathrm{HN}$, which probably gave rise to those antigenic differences.

Conclusion: Our result suggested that the PPMV-1 strain prevailing in China in the last decade diverged from a common ancestor and was presumably transmitted from Europe. PPMV-1 isolates displayed obvious antigenic differences from vaccine strain LaSota. Even though PPMV-1 did not cause high mortality in experimental pigeons, the infected pigeons were exhibiting viral shedding for 3 weeks after infection, suggesting PPMV-1 is a potential threat to NDV control worldwide.
\end{abstract}

Keywords: Newcastle disease virus, Pigeon, Virulence, Phylogenetic analysis, Antigenic differences

\section{Background}

Newcastle disease (ND) in pigeons is responsible for one of the most severe recent infectious pigeon diseases in China [1-3]. The causative agent of ND in pigeons is Newcastle disease virus (NDV), also called pigeon paramyxovirus type 1 (PPMV-1). NDV is taxonomically classified into the genus

\footnotetext{
* Correspondence: shoveldeen@shvri.ac.cn

'Shanghai Veterinary Research Institute, Chinese Academy of Agricultural Sciences, Shanghai 200241, People's Republic of China

${ }^{3}$ Jiangsu Co-innovation Center for Prevention and Control of Important Animal Infectious Diseases and Zoonoses, Yangzhou, Jiangsu, China Full list of author information is available at the end of the article
}

Avulavirus, subfamily Paramyxovirinae, family Paramyxoviridae, order Mononegaviriales [4, 5]. The NDV genome consists of a single-stranded, negative-sense RNA, containing six genes in the sequence of $3^{\prime}-\mathrm{NP}-\mathrm{P}-\mathrm{M}-\mathrm{F}-\mathrm{HN}-\mathrm{L}-5^{\prime}$. Six structural proteins are encoded as nucleoprotein (NP), phosphoprotein $(\mathrm{P})$, matrix protein $(\mathrm{M})$, fusion protein $(\mathrm{F})$, hemagglutinin-neuraminidase $(\mathrm{HN})$ and large protein $(\mathrm{L})$ [6]. In addition, two nonstructural proteins, $\mathrm{V}$ and $\mathrm{W}$, are generated from the P gene by RNA editing $[7,8]$.

NDV isolates are phylogenetically divided into two major classes, class I and class II $[9,10]$. Class I NDV 
isolates are widely separated from healthy birds, and nearly all are nonvirulent [10-14]. NDVs belonging to class I are characterized by a 15,198-nt genomic RNA. By contrast, class II NDVs have two genome types. According to the classification system proposed by Claudio L. Afonso et al. in 2012, class I viruses contain a single genotype whereas class II NDV isolates can be effectively divided in 18 genotypes (I - XVIII) [15]. Genotype I-IV viruses are early lineage (before 1960) with a genome size of 15,186 nt. Genotype V-VIII are recent lineage (after 1960) with a genome of 15,192 nt [4, 10, 16-18]. Most pigeon-derived virulent NDV isolates are class II genotype VI, which was further divided into VIa - VIg. Subtype VIa strains, with the representative strain Iraq AG68, were isolated from Middle Eastern epizootics in the 1960s and subsequently spread to Africa and Asian countries [19]. Subtype VIb NDV of pigeon origin is widely accepted to be responsible for the third ND pandemic during the 1980s. In a Chinese outbreak around 2000, subgenotype VIb [20], VIf and VIg [19] were all identified from pigeons, chickens and other fowls, whereas in the last decade, little VIf and VIg outbreaks have been reported [21].

Based on the pathogenicity of ND strains in chickens, NDV isolates are generally classified as lentogenic (nonvirulent), mesogenic (intermediate virulent) and velogenic (highly virulent), which are further classified as viscerotropic velogenic and neurotropic velogenic [22]. The virulence of NDV strains is reported to be mainly determined by cleavage site sequence of the $\mathrm{F}$ protein $[23,24]$. NDV F protein is generated as precursor F0; when cleaved into disulfide-linked F1 and F2 polypeptides, F protein changes to be fusogenic and is crucial in mediating fusion of the viral envelope with cellular membranes. The consensus sequence of $\mathrm{F}$ protein cleavage sites of velogenic and mesogenic strains is ${ }^{112}(\mathrm{R} / \mathrm{K}) \mathrm{RQ}(\mathrm{R} / \mathrm{K}) \mathrm{RF}^{117}$. Common lenogenic strains have a monobasic amino acid motif at the same site, ${ }^{112}(\mathrm{G} / \mathrm{E})(\mathrm{K} / \mathrm{R}) \mathrm{Q}(\mathrm{G} / \mathrm{E}) \mathrm{R} \downarrow \mathrm{L}^{117}$. Different $F$ protein cleavage sites are substrates for different types of cellular proteases $[25,26]$. The $\mathrm{F}$ protein of lentogenic strains is cleaved only by trypsin-like enzymes, which are confined to the respiratory and intestinal tracts. The $\mathrm{F}$ protein of virulent viruses such as genotype VI and VII strains are cleaved by ubiquitous and diverse host protease(s). Based on these findings, virulent NDV is defined by the World Organization for Animal Health as a virus of avian paramyxovirus-1 (APMV-1) with at least three multiple basic amino acids (arginine or lysine) residues at the C-terminus of the F2 protein (between residues 113 and 116) and phenylalanine at residue 117, which is the N-terminus of the F1 protein [22, 27].

For many years, ND has been one of the most important infectious pigeon diseases in China, but low mortality of this disease is widely reported in most countries. After infection with pigeon-origin genotype VI ND, pigeons showed clinical signs similar to neurotropic ND-infected chickens, with a morbidity from $30 \%$ to $70 \%$ and a mortality no more than $10 \%[28,29]$. In recent years, a high mortality has been observed in ND-infected pigeons in China. Mortality is from $40 \%$ to $80 \%$ or $100 \%$ in some cases [1-3]. Whether pigeon-origin NDV isolates in China are more pathogenic for pigeons remains unclear. In this study, we analyzed genomic sequences of four PPMV-1 strains recently isolated in China, furthermore, the virulence, antigenicity and potential threat of the viruses were evaluated.

\section{Methods}

\section{Viruses and pathogenicity tests}

Pigeon-origin NDV strains pi/SD/CH/0132/2012 (designated ND132 in this study), pi/SH/CH/0163/2012 (ND163), pi/SH/CH/0167/2013 (ND167), and pi/SH/CH/ 0168/2013 (ND168) were isolated from clinical specimens of diseased pigeons in Shanghai and Shandong Provinces in China in 2012 and 2013. F48E8 (eighth egg-passaged stock of F48), the standard ND challenge strain in China [19] and chicken vaccine strain LaSota were from the China Institute of Veterinary Drug Control (Beijing, China). All viruses were propagated in 9- to 11-day-old specific-pathogen-free (SPF) chicken embryonated eggs as described [30]. Fresh allantoic fluid was harvested from embryonated eggs dead between 24 and $120 \mathrm{~h}$ after inoculation, and kept at $-80{ }^{\circ} \mathrm{C}$. Mean death time (MDT) and intracerebral pathogenicity index (ICPI) tests were determined as previously described to determine the virulence of the four isolates [27].

\section{Viral RNA extraction, RT-PCR and full-length genome sequencing}

The genomic RNA of ND132, ND163, ND167, and ND168 was extracted from the allantoic fluid of infected eggs using TRIzol reagent (Invitrogen, Carlsbad, CA, USA), according to the manufacturer's instructions. RNA pellets were resuspended in $50 \mu \mathrm{L}$ RNase-free water and reverse transcribed with 6-nt random primer with Mo-MLV reverse transcriptase (Promega, Madison, WI, USA). The cDNA was used as template to generate nine successive and overlapping DNA fragments by PCR using primer pairs specific for genotype VI NDV strains (Additional file 1: Table S1). Reverse transcription and PCR was performed without modification as described [31].

To determine the $3^{\prime}$ - and $5^{\prime}$-ends of the viral genomes, rapid amplification of CDNA end (RACE) was performed as reported previously [32]. For 3'-RACE, genomic RNA was ligated with 5'-end-phosphorylated adaptor CL+ (Additional file 1: Table S1) using T4 RNA ligase (Fermentas, Shenzhen, China) in the presence of RNasin (Takara Biotechnology, Dalian, China) at $1 \mathrm{U} / \mu \mathrm{l}$. After denaturation at $75{ }^{\circ} \mathrm{C}$ for $15 \mathrm{~min}$, ligated RNA was 
transcribed with anti-adaptor CL- using Mo-MLV Reverse Transcriptase, which was complementary to adaptor primer CL+. The 3'-end of the genome was PCR-amplified with CL- and 3TSR, which was specific for the NP gene.

For 5'-RACE, first-strand cDNA was reverse-transcribed from viral RNA using specific primer 5TLF. After treatment with an equal volume of $0.6 \mathrm{~N} \mathrm{NaOH}$ for 20 min at $60{ }^{\circ} \mathrm{C}$ to hydrolyze mRNA, cDNA was ligated with adaptor $\mathrm{CL}+$ using T4 RNA ligase. Adaptor-ligated cDNA was PCR-amplified using primer 5TLF and anti-adaptor primer $\mathrm{CL}$ - and $1 \mu \mathrm{l}$ PCR products was used for a second-round hemi-nested PCR reaction with primer CL- and specific primer 5TSF to generate the $5^{\prime}$ end of the viral genome.

PCR products were extracted from agarose gels and ligated into the TA cloning system (Promega). Ligation products were transferred into Escherichia coli DH5 $\alpha$ and identified by restriction enzyme analysis. At least five clones for each segment were sent to Sangon Biotechnology (Shanghai, China) for sequencing.

\section{Sequence analysis}

Prediction of amino acid sequences, alignment of sequences and phylogenetic analysis was performed using the MegAlign program in the Lasergene package (DNASTAR Inc. Madison, WI, USA). Phylogenetic trees were constructed using MEGA version 7 [33]. The genome sequences of 37 reference NDV strains, and the F gene sequences from 360 genotype VI NDV isolates and 24 other genotype representative strains were from EMBL/GenBank [31, 34]. All data and accession numbers of NDV strains used in this study are listed in Additional file 2: Table S2.

\section{Cross hemagglutination inhibition and cross virus- neutralization tests}

Cross hemagglutination inhibition test was performed as described [3] using four hemagglutinating units of LaSota, ND167 or ND132 virus and antisera against the NDV strains. For cross virus-neutralization (VN) tests, the $50 \%$ embryo infectious dose $\left(\mathrm{EID}_{50}\right)$ value of LaSota, ND167 and ND132 viruses was determined in advance by inoculation at a 10-fold dilution into 10-day-old SPF embryonated chicken eggs. Antisera against LaSota, ND167 and ND132 were serially double-diluted and mixed respectively with each NDV strain at $100 \mathrm{EID}_{50} /$ $100 \mu \mathrm{l}$. After incubation at $4{ }^{\circ} \mathrm{C}$ for $1 \mathrm{~h}$, mixtures were injected into five, 10-day-old SPF embryonated chicken eggs to determine neutralization levels. Results of crossVN and cross-HI tests were expressed as average and standard deviation (SD) and $R$-value was calculated using the formula of Archetti and Horsfall [35].

Antisera used in this study were obtained from chickens and pigeons according to a previous report [1], with minor modification. First, 30-day-old SPF chickens and 50-day-old clinically healthy pigeons were intramuscularly injected with inactive oil-emulsified LaSota, ND167 or ND132 strains $\left(10^{6} \mathrm{EID}_{50}\right.$ per chick and $10^{5} \mathrm{EID}_{50}$ per pigeon). After 2 weeks, booster doses were administered. Birds were exsanguinated for serum collection 1 week after last inoculation. All sera were inactivated at $56{ }^{\circ} \mathrm{C}$ for $30 \mathrm{~min}$ and stored at $-80{ }^{\circ} \mathrm{C}$.

\section{Animal experiment design}

A total of 56 clinically healthy 40-day-old pigeons without any antibodies against ND were used and housed in negative pressure isolators (Fengshi Group, Suzhou, China). Experiments were carried out in strict accordance with the recommendations in the Guide for the Care and Use of Laboratory Animals of Shanghai Veterinary Research Institute, Chinese Academy of Agricultural Sciences. Samples were collected from three pigeons randomly chosen before experiments and all pigeons after experiments were detected for other pigeon viruses by multiplex PCR [36]. All pigeons were free of pigeon herpesvirus, adenovirus and circovirus (data not shown).

Pigeons were randomly divided into eight groups of seven birds per group: groups A1, A2, A3, B1, B2, B3, $\mathrm{PC}$ and NC. All pigeons were inoculated with $0.2 \mathrm{ml} 10^{6}$ $\mathrm{EID}_{50}$ virus via intravenous injection (groups A1 and B1), intramuscular injection (groups A2 and B2) or oral administration (groups A3 and B3). The titers of undiluted virus stock of ND132, ND167 and F48E8 were determined as $10^{7.3} \mathrm{ELD}_{50} / 0.2 \mathrm{ml}, 10^{7.9} \mathrm{ELD}_{50} / 0.2 \mathrm{ml}$ and $10^{8.3} \mathrm{ELD}_{50} / 0.2 \mathrm{ml}$ respectively. Pigeons in a positive control (PC) group were intramuscularly injected with $10^{6} \mathrm{EID}_{50}$ F48E8; pigeons in negative control (NC) group were inoculated with sterile PBS ( $\mathrm{pH}$ 7.2). Immediately after virus inoculation, all pigeons were kept in negative pressure isolators (Fengshi Group), under controlled laboratory and biosafety conditions. Pigeons were observed twice a day for 42 days, and any abnormal posture or behavior was recorded. Oral and cloacal swabs were collected at 5, 7, 10, 14, 21, 28, 35 and 42 days post infection (dpi) from experimental pigeons. Collected swabs were placed in $1.0 \mathrm{ml}$ sterile $\mathrm{PBS} \mathrm{pH} 7.2$ and kept in $-80^{\circ}$ C. Virus shedding was determined by virus isolation from swabs, using three SPF chicken eggs per sample.

\section{Results}

\section{Sequence characteristics of the four PPMV-1 isolate genomes}

RT-PCR was performed for amplification of the expected nine overlapping fragments and the $5^{\prime}$ and $3^{\prime}$ ends of the genomes using respective primers in Additional file 1: Table S1. Amplified products were sequenced, aligned and assembled to obtain the full-length genome of four PPMV-1 strains. Sequences were submitted to EMBL/ GenBank with the following accession numbers: 
KT163261 for ND163, KT163262 for ND167, KT163263 for ND168 and KT163264 for ND132. All the four genomes were 15,192 nucleotides (nt) in length, as reported for all other genotype VI NDV strains [27]. Compared with the genome of genotype I, II, and III NDV strains, all four isolates had a 6-nt insertion, CCCCAA, at position 1647 of the viral genome in the $5^{\prime}$-noncoding region of the NP gene. Phylogenetic analysis was performed using the complete genome sequences of the four NDV isolates, all of which were characterized as genotype VI (Fig. 1).

The proteolytic cleavage site motif (residues 112-117) of the F protein from the four PPMV-1 isolates was determined as ${ }^{112} R R Q K R \downarrow F^{117}$, the typical virulence motif [27]. Six predicted $\mathrm{N}$-glycosylation sites, ${ }^{85} \mathrm{NRT}^{87},{ }^{191} \mathrm{NNT}^{193}$, ${ }^{366} \mathrm{NTS}^{368},{ }^{447} \mathrm{NIS}^{449},{ }^{471} \mathrm{NNS}^{473}$ and ${ }^{497}{ }^{\mathrm{NTS}^{499}}$, were found in the F protein of all four isolates. The HN of the four PPMV-1 isolates was sequenced as 571 amino acid (aa) with five predicted $\mathrm{N}$-glycosylation sites at ${ }^{119} \mathrm{NNS}^{121}$, ${ }^{341} \mathrm{NNT}^{343},{ }^{433} \mathrm{NKT}^{435},{ }^{481} \mathrm{NHT}^{483}$ and ${ }^{508} \mathrm{NIS}^{510}$; which are conserved in PPMV-1 strains [37].

The nucleotide and amino acid sequences of the four PPMV-1 isolates were compared. In general, the six coding-region sequences showed very low divergence. The six genes of three Shanghai NDV isolates, ND163, ND167, and ND168, shared more than $99.9 \%$ identity for nucleotides and amino acids. ND132 showed lower homology to the three Shanghai NDV isolates. Shared nucleotide identities for ND132 and ND167 were 96\% for the NP gene, $92.9 \%$ for P gene, $94.2 \%$ for M gene, 95.7\% for F gene, $94.4 \% \mathrm{HN}$ gene and $96 \%$ for L gene, and amino acid identities for ND132 and ND167 were 98.4\% for NP protein, $93.2 \%$ for P protein, $93.2 \%$ for M protein, $97.3 \%$ for F protein, $96.9 \%$ for HN protein, and 98.7\% for L protein. According to Basic Local Alignment Search Tool (BLAST) of NCBI, both full-length genomes of ND132 and ND167 showed a very high similarity to PPMV-1 strains isolated in China in recent decades. The Chinese strains with highest homology were $\mathrm{pi} / \mathrm{CH} /$ LGD/110947 (accession number JX486556.1, 99.0\% compared with ND132) and pigeon/China/SDLC/2011 (accession number JQ979176.1, 99.5\% compared with ND167), both of which were isolated in China in 2011 [38]. The foreign strains that shared highest nucleotide homology were PPMV-1/Belgium/11-08304/2011 (JX901123.1) which had $99.0 \%$ identity with the three Shanghai NDV isolates.

\section{Phylogenetic analysis of pigeon-origin NDV isolates pre- vailing in China}

Further phylogenetic analysis based on the variable region sequences (nt 47-420) of the $F$ gene from 384 APMV-1 isolates showed that the four PPMV-1 isolates in this study were categorized as genotype VIb (Fig. 2). For this phylogenetic tree, nearly all pigeon-origin strains available in GenBank were collected. The tree displayed a relationship of the genotypes of NDV isolates and the time they were isolated. While subgenotype VIb [20], VIf and VIg [19] pigeon NDV were commonly isolated before 2000, VIb subtype NDV were predominantly identified from Chinese pigeons in China in recent two decades. Only one strain, pi/China/Shaanxi/g10/2006 [21], shared high nucleotide homology with subgenotype VIf and VIg.

In 2004, Aldous et al. systematically analyzed the phylogenesis of genotype VI NDV strains and divided the VIb subgenotype into groups 4bi and 4bii; the latter was further classified into clades d, e, f [34]. PPMV-1 isolates in China did not belong to group 4bi and clade 4bii e, and had further genetic distance from VIb NDV isolates in North America and Japan (Fig. 2).

Most of the PPMV-1 isolates in China after 2000 (Fig. 2) were classified into clade $4 \mathrm{bii} \mathrm{f}$, which was further divided into three clades (Fig. 3). Our NDV isolate ND132 and other NDV isolates in distant provinces such as JS/07/03/ $\mathrm{Pi}, \mathrm{pi} / \mathrm{GX} / 1015 / 13$ and $\mathrm{pi} / \mathrm{CH} / \mathrm{LGD} / 110945$, were highly homologous and in the same clade as P4 and W4; these were isolated from wild water birds in South China and deduced to be from Europe around 1999 [39]. The other Chinese isolates shared higher homology with Belgium/ 11-09620, Belgium/11-08304 and Belgium/11-07574, and showed further genetic distance from $\mathrm{P} 4$ and $\mathrm{W} 4$. This result suggested they may be directly derived from Europe but not from the local Chinese epidemic strains.

To further determine the homology of the four NDV isolates with previous isolates, the nucleotide and amino acid homologies of six viral genes were compared. Similar to the phylogenetic analysis, ND132 showed highest homology with Belgium/11-09620 (Additional file 3: Table S3). The other three Shanghai isolates, ND163,ND167 and ND168 were closest to P4 strain (Additional file 4: Table S4). No virulence-related differences were found between the European strains and our four isolates, which can be assumed to be representative of PPMV-1 prevailing in China in recent decade.

Based on sequence alignment, amino acid differences in surface glycoproteins between recent PPMV-1 isolates and the classic vaccine strain LaSota were identified. Specific substitutions for ND167 and ND132 are in Table 1 . In the $\mathrm{F}$ protein of Belgium/11-like PPMV-1 strains, five specific substitutions were found: M14 T, P28S, V179I, A203S and V506I; only one specific substitution, I432V, was found in P4-like PPMV-1 strains. When the HN protein sequences were aligned and compared, I59V, A66V, L74I, T232 N, S432H, A497T and D569E were found in Belgium/11-like PPMV-1 strains; I84V and A145V were in P4-like PPMV-1 isolates. For all substitutions, V179I and V506I of $\mathrm{F}$ protein were located in the heptad repeat region a ( $\mathrm{HRa}$, aa 143-185) 


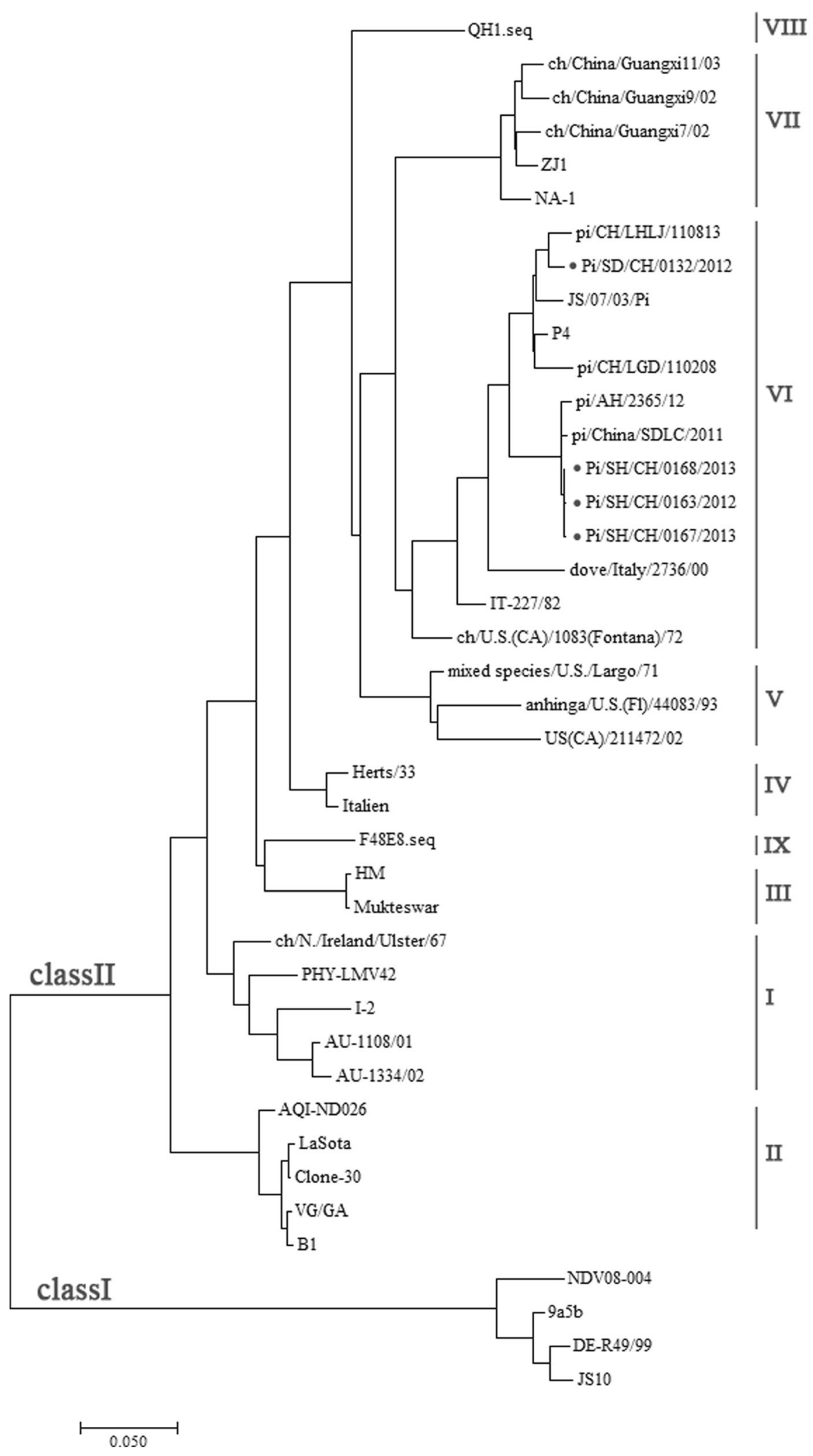

Fig. 1 Phylogenetic tree based on full-length nucleotide sequences of NDV strains. The tree of 41 nucleotide sequences was constructed using MEGA7 [33]. Strain genotypes are marked on the right. The GenBank accession numbers of the reference NDV strains are listed in Additional file 2: Table S2. ${ }^{*}$, the strains investigated in this study 


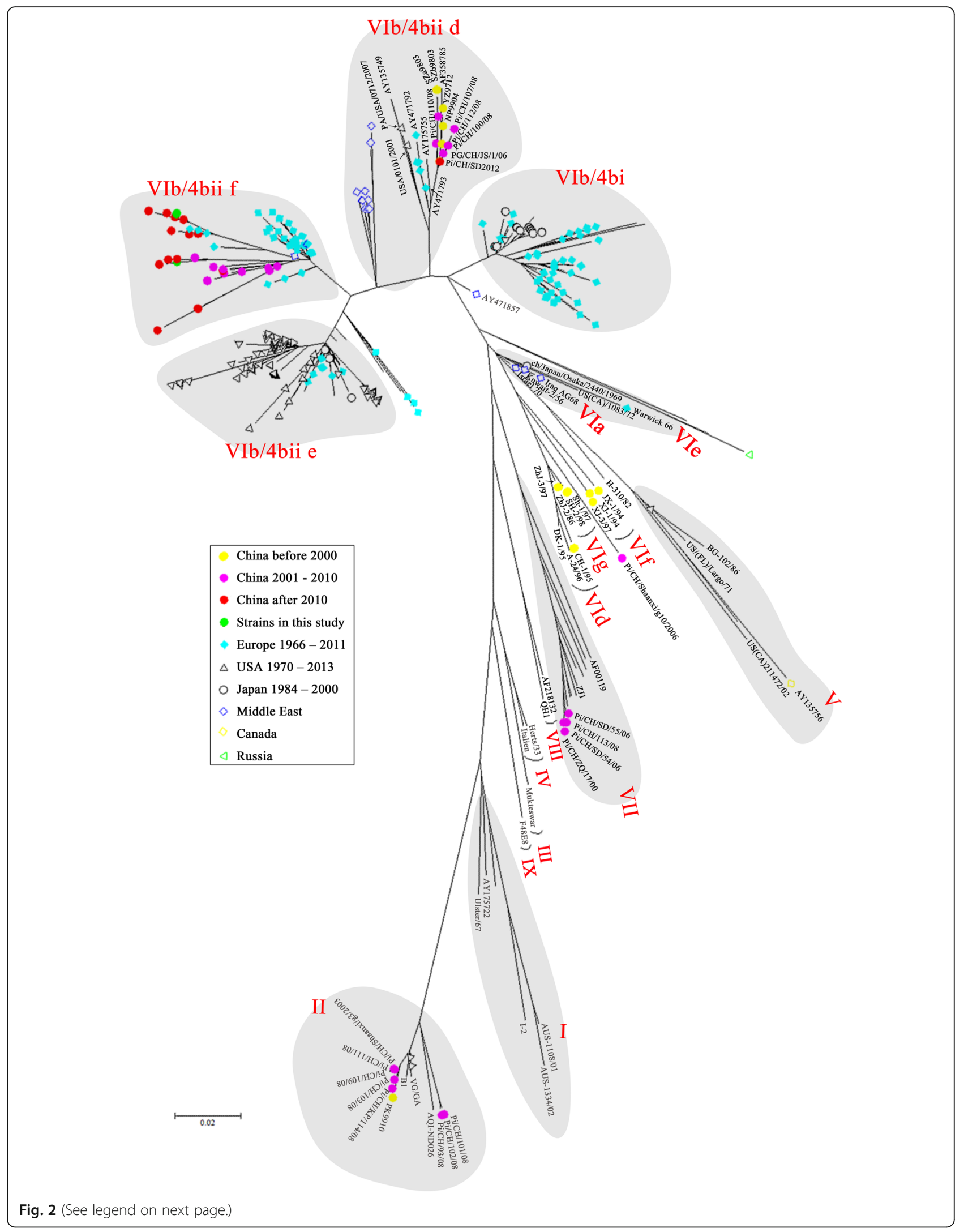


(See figure on previous page.)

Fig. 2 Unrooted maximum likelihood radial phylogram of the isolate genotypes. The tree was constructed on a 374-nt section of the F gene sequences from 360 genotype VI NDV isolates and 24 other genotypes representative strains in GenBank, and relevant evolutionary analyses were conducted in MEGA7 [33]. The tree is to scale, with branch lengths measured in number of substitutions per site. Names of each PPMV-1 strain are not shown but represented by colored symbols. Genotypes and groups of each clade are labeled. All data and accession numbers for reference $F$ gene sequences of the isolates and strains were from EMBL/GenBank based on established phylogenic analysis (Additional file 2: Table S2)

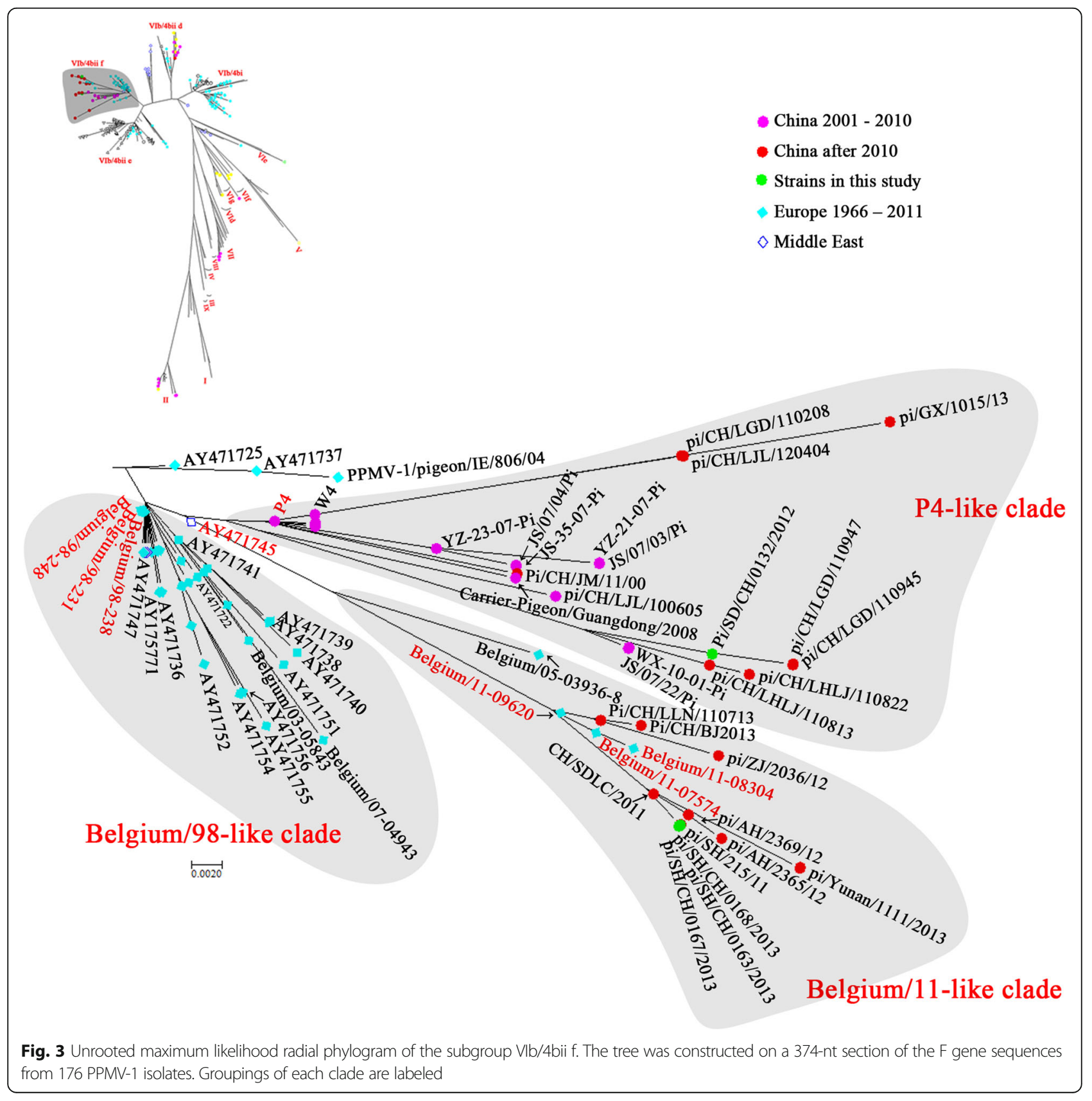


Table 1 Specific amino acid substitutions in F and HN proteins of endemic PPMV-1 strains in China compared to LaSota. Amino acids that are the same as LaSota are indicated by "-"

\begin{tabular}{|c|c|c|c|c|c|c|c|c|c|c|c|c|c|c|c|c|c|c|c|c|c|c|c|c|c|}
\hline \multirow[t]{2}{*}{ Subgenotype } & \multirow[t]{2}{*}{ clade } & \multirow[t]{2}{*}{ strains } & \multicolumn{11}{|c|}{$\mathrm{F}$ protein } & \multicolumn{12}{|c|}{ HN protein } \\
\hline & & & 6 & 8 & 13 & 14 & 16 & 28 & 179 & 203 & 259 & 432 & 506 & 59 & 66 & 74 & 84 & 121 & 145 & 232 & 263 & 309 & 432 & 497 & 569 \\
\hline$\|$ & & LaSota & $\mathrm{S}$ & $\mathrm{K}$ & $M$ & $M$ & $T$ & $P$ & V & $A$ & $Q$ & I & $\mathrm{V}$ & I & $A$ & $\mathrm{~L}$ & 1 & 1 & $A$ & $\bar{T}$ & $\mathrm{~N}$ & $\mathrm{D}$ & $S$ & $A$ & $\mathrm{D}$ \\
\hline \multirow[t]{15}{*}{ Vlb/4bii f } & \multirow[t]{7}{*}{$\begin{array}{l}\text { Belgium/ } \\
\text { 11-like }\end{array}$} & $\begin{array}{l}\mathrm{pi} / \mathrm{SH} / \\
\mathrm{CH} / 0163 / \\
2012\end{array}$ & $\mathrm{H}$ & $\mathrm{R}$ & $P$ & $\mathrm{~T}$ & I & $S$ & I & S & $\mathrm{H}$ & - & 1 & V & V & I & - & - & । & $\mathrm{N}$ & K & - & $\mathrm{H}$ & $\mathrm{T}$ & $\mathrm{E}$ \\
\hline & & $\begin{array}{l}\mathrm{pi} / \mathrm{SH} / \\
\mathrm{CH} / 0167 / \\
2013\end{array}$ & $\mathrm{H}$ & $\mathrm{R}$ & $P$ & $\mathrm{~T}$ & I & S & I & S & $\mathrm{H}$ & - & 1 & V & V & I & - & - & I & $\mathrm{N}$ & K & - & $\mathrm{H}$ & $\mathrm{T}$ & $\mathrm{E}$ \\
\hline & & $\begin{array}{l}\mathrm{pi} / \mathrm{SH} / \\
\mathrm{CH} / 0168 / \\
2013\end{array}$ & $\mathrm{H}$ & $\mathrm{R}$ & $P$ & $\mathrm{~T}$ & । & $S$ & । & S & $\mathrm{H}$ & - & 1 & V & V & I & - & - & । & $\mathrm{N}$ & K & - & $\mathrm{H}$ & $\mathrm{T}$ & $E$ \\
\hline & & $\begin{array}{l}\text { pi/YN/ } \\
1111 / 13\end{array}$ & $\mathrm{H}$ & $\mathrm{R}$ & $P$ & $\mathrm{~T}$ & 1 & $S$ & 1 & S & $\mathrm{H}$ & - & 1 & V & V & 1 & - & - & 1 & $\mathrm{~N}$ & K & - & $\mathrm{H}$ & $\mathrm{T}$ & $\mathrm{E}$ \\
\hline & & $\begin{array}{l}\mathrm{pi} / \mathrm{AH} / \\
2365 / 12\end{array}$ & $\mathrm{H}$ & $\mathrm{R}$ & P & $\mathrm{T}$ & I & $S$ & 1 & S & $\mathrm{H}$ & - & 1 & V & V & 1 & - & - & I & $\mathrm{N}$ & K & - & $\mathrm{H}$ & $\mathrm{T}$ & $\mathrm{E}$ \\
\hline & & $\begin{array}{l}\text { Belgium/ } \\
11- \\
09620 / \\
2011\end{array}$ & $\mathrm{H}$ & $\mathrm{R}$ & $\mathrm{L}$ & $\mathrm{T}$ & 1 & $S$ & I & S & $\mathrm{H}$ & - & 1 & V & V & 1 & - & - & 1 & $\mathrm{~N}$ & K & - & $\mathrm{H}$ & $\mathrm{T}$ & $E$ \\
\hline & & $\begin{array}{l}\text { Belgium/ } \\
11- \\
07574 / \\
2011\end{array}$ & $\mathrm{H}$ & $\mathrm{R}$ & $\mathrm{L}$ & $\mathrm{T}$ & I & $S$ & I & S & $\mathrm{H}$ & - & 1 & V & V & I & - & - & 1 & $\mathrm{~N}$ & K & - & $\mathrm{H}$ & - & $E$ \\
\hline & \multirow[t]{5}{*}{ P4-like } & P4 & $\mathrm{H}$ & $\mathrm{R}$ & $\mathrm{L}$ & - & 1 & $\mathrm{~L}$ & - & $\mathrm{T}$ & $\mathrm{H}$ & V & - & - & - & - & V & V & V & - & K & $N$ & $Y$ & - & - \\
\hline & & $\begin{array}{l}\mathrm{pi} / \mathrm{SD} / \\
\mathrm{CH} / 0132 / \\
2012\end{array}$ & $\mathrm{H}$ & G & $\mathrm{L}$ & - & V & $\mathrm{L}$ & - & $\mathrm{T}$ & - & V & - & - & - & - & V & V & V & - & $\mathrm{R}$ & $N$ & Y & - & - \\
\hline & & $\begin{array}{l}\text { JS/07/22/ } \\
\mathrm{Pi}\end{array}$ & $\mathrm{H}$ & $\mathrm{R}$ & $\mathrm{L}$ & - & V & $\mathrm{L}$ & - & $\mathrm{T}$ & - & V & - & - & - & - & V & V & V & - & $\mathrm{R}$ & $\mathrm{N}$ & Y & - & - \\
\hline & & $\begin{array}{l}\mathrm{pi} / \mathrm{CH} / \\
\mathrm{LHLJ} / \\
110822\end{array}$ & $\mathrm{H}$ & $\mathrm{R}$ & $\mathrm{L}$ & - & V & $\mathrm{L}$ & - & $\mathrm{T}$ & - & V & - & - & - & - & V & V & V & - & $\mathrm{R}$ & $N$ & Y & - & - \\
\hline & & $\begin{array}{l}\mathrm{pi} / \mathrm{CH} / \\
\mathrm{LGD} / \\
110947\end{array}$ & $\mathrm{H}$ & G & $P$ & - & V & $L$ & - & $\mathrm{T}$ & - & V & - & - & - & - & V & V & V & - & $\mathrm{R}$ & $N$ & Y & - & - \\
\hline & \multirow[t]{3}{*}{$\begin{array}{l}\text { Belgium/ } \\
\text { 98-like }\end{array}$} & $\begin{array}{l}\text { Belgium/ } \\
98-238 / \\
1998\end{array}$ & $Y$ & $\mathrm{R}$ & $\mathrm{L}$ & - & I & $L$ & - & $\mathrm{T}$ & - & V & - & - & - & - & - & V & I & - & K & $N$ & Y & - & - \\
\hline & & $\begin{array}{l}\text { Belgium/ } \\
98-248 / \\
1998\end{array}$ & $Y$ & $\mathrm{R}$ & $\mathrm{L}$ & - & I & L & - & T & - & V & - & - & - & - & - & V & I & - & K & $N$ & Y & - & - \\
\hline & & $\begin{array}{l}\text { Belgium/ } \\
\text { 07- } \\
04943 / \\
2007\end{array}$ & Y & $\mathrm{R}$ & $\mathrm{L}$ & - & I & $\mathrm{L}$ & - & $\mathrm{T}$ & - & V & - & - & - & - & - & V & I & - & K & $N$ & Y & - & - \\
\hline Vlb/4bii d & & $\begin{array}{l}\text { Pigeon/ } \\
\text { China/ } \\
\text { SD2012 }\end{array}$ & - & $\mathrm{R}$ & $P$ & - & I & - & - & T & $\mathrm{H}$ & - & - & - & $\mathrm{T}$ & - & - & V & $\mathrm{T}$ & - & K & - & Y & - & - \\
\hline Vlb/4bi & & IT-227/82 & - & $\mathrm{R}$ & $\mathrm{L}$ & $T$ & I & - & - & T & $\mathrm{H}$ & - & - & - & $\mathrm{T}$ & - & - & V & $\mathrm{T}$ & - & K & - & $\mathrm{H}$ & - & G \\
\hline Vle & & $\begin{array}{l}\text { US }(C A) / \\
1083 \\
\text { Fontana/ } \\
72\end{array}$ & - & $\mathrm{R}$ & $\mathrm{L}$ & - & I & $\mathrm{L}$ & - & $\mathrm{T}$ & - & - & - & - & $\mathrm{T}$ & - & - & V & $\mathrm{T}$ & - & K & - & Y & - & - \\
\hline
\end{tabular}


and transmembrane domain (aa 501-521); N263 K and D569E substitutions in Belgium/11-like PPMV-1 strains and N263R in P4-like PPMV-1 isolates were identified in neutralizing epitopes [3].

\section{Cross hemagglutination inhibition and cross virus neutralization assays}

To determine the reactivity of anti-NDV serum with different isolates, cross-HI assay was carried out. Antiserum from chickens reacted with both heterologous and homologous antigens and all HI titers using homologous antigens were slightly higher than titers using other antigens (Fig. 4). $R$ values for comparisons to the LaSota strain were 0.669 for ND132 and 0.616 for ND167, suggesting minor antigenic differences of the epidemic PPMV-1 isolates with the commonly used LaSota vaccine. Reactivity differences for pigeon sera with different isolates were more obvious. Anti-ND132 and anti ND167 pigeon serum rarely reacted with LaSota since $\mathrm{HI}$ titers of those sera with homologous antigens were $2^{3.6}$ and $2^{4.8} . R$ values for LaSota strain were 0.287 for ND132 and 0.308 for ND167 using pigeon-derived serum, indicating definite antigenicity differences between these strains.

Chicken antisera against LaSota, ND132 and ND167 were used in cross-VN assays to further determine antigenicity differences among ND132, ND167 and LaSota (Table 2). The 50\% endpoints were calculated according to the Reed and Muench method [40]. Against homologous strains ND132 and LaSota, neutralization titers of anti-ND167 serum were 1:189, 1:51 and 1:25. $R$ values for comparisons to ND167 were 0.208 for LaSota and 0.412 for ND132, indicating striking antigenic differences of ND167 with other strains.
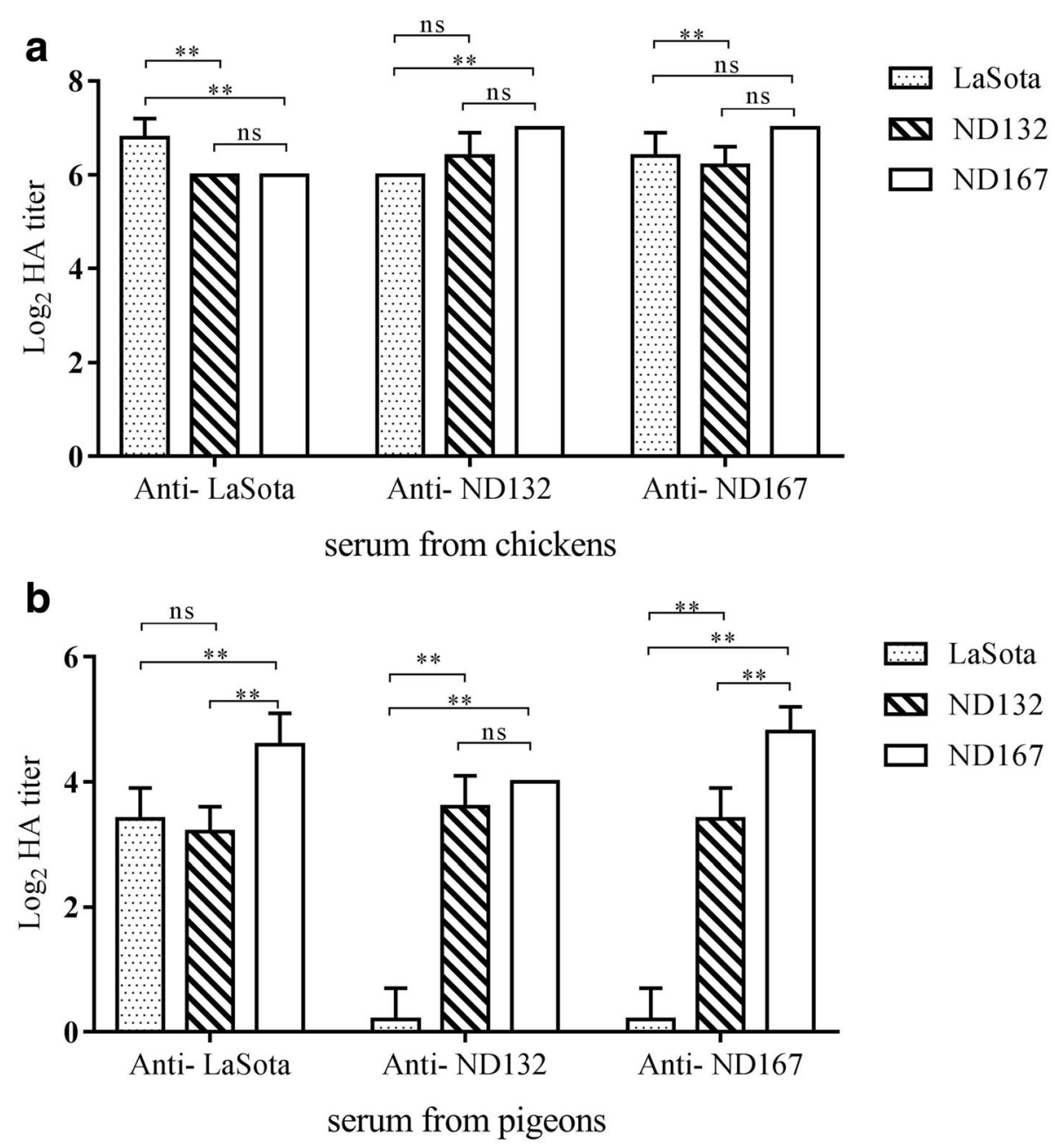

Fig. 4 Cross hemagglutination inhibition values for anti-NDV chicken sera (a) and pigeon sera (b) against Lasota, ND167 and ND132. Data are presented as mean \pm standard deviation. The statistical differences between each group of values were determined by two-way ANOVA and labeled in the figures. ${ }^{*} P<0.05 ;{ }^{* *} P<0.01 ; \mathrm{ns}$, no significant difference) 
Table 2 Cross virus-neutralization titers for anti-NDV sera against LaSota, ND167 and ND132 in embryonated chicken eggs

\begin{tabular}{llll}
\hline Anti-serum & NDV strain & & \\
\cline { 2 - 4 } & La Sota & ND132 & ND167 \\
\hline Anti-LaSota & $1: 288$ & $1: 102$ & $1: 94$ \\
Anti-ND132 & $1: 150$ & $1: 256$ & $1: 161$ \\
Anti-ND167 & $1: 25$ & $1: 51$ & $1: 189$ \\
\hline
\end{tabular}

\section{Pathogenicity studies}

ND132, ND163, ND167 and ND168 were subjected to pathogenicity index tests using chickens. The MDT of all four isolates was in 60-90 h, and the ICPI index was between 0.7 and 1.5 (Table 3) [41].

To determine the mortality of PPMV-1 prevailing in China in recent decade, pigeons were infected with ND132 in the Belgium-11-like clade and ND167 in the P4-like clade. At $5 \mathrm{dpi}$, infected pigeons were depressed and displayed ruffled feathers and transient fever. Pigeons infected with ND132 or ND167 recovered at 7 dpi, and showed no clinical symptoms. In F48E8 infected group, three pigeons died at 5 or $8 \mathrm{dpi}$. No apparent clinical signs were observed in pigeons of the negativecontrol group.

To determine viral shedding, oropharyngeal and cloacal swabs were taken on $5,7,10,14,21,28,35$ and 42 dpi. The samples were subjected for NDV isolation using SPF embryonated eggs (Table 4). Virus shedding from pigeon throats was detectable from all seven infection groups at $5 \mathrm{dpi}$, especially in the two groups infected via intravenous injection. The highest shedding rates were observed from the throat at $7 \mathrm{dpi}$ and cloaca at $10 \mathrm{dpi}$. Viral shedding reduced at $14 \mathrm{dpi}$ and ceased at $21 \mathrm{dpi}$. Mock-inoculated pigeons remained virus negative throughout the experiments.

\section{Discussion}

Four virulent PPMV-1 strains, ND132, ND163, ND167 and ND168, were isolated in Chinese pigeon farms; $70-80 \%$ of raised pigeons died from the outbreaks [41]. The genomes of the viruses were sequenced and subjected to phylogenetic analysis with sequences from 380 NDV strains isolated from China, Japan, the Middle East, Europe and North America. Based on analysis of six viral proteins, all four isolates were classified into subgenotype VIb and had high homology to most PPMV-1 strains isolated after 2000 from

Table 3 Pathogenicity indexes for PPMV-1 isolates in this study

\begin{tabular}{llll}
\hline Strain & HA titer & MDT & ICPI \\
\hline ND132 & $2^{6}$ & $66 \mathrm{~h}$ & 0.95 \\
ND163 & $2^{7}$ & $62 \mathrm{~h}$ & 1.15 \\
ND167 & $2^{7}$ & $60 \mathrm{~h}$ & 1.21 \\
ND168 & $2^{7}$ & $65 \mathrm{~h}$ & 1.18 \\
\hline
\end{tabular}

Table 4 Viral shedding of PPMV-1 from the oral cavity and cloaca of experimentally infected pigeons. Pigeons in groups A1, $\mathrm{A} 2$ and $\mathrm{A} 3$ were infected with $10^{6}$ EID 50 pi/China/SD/2012/132; pigeons in groups B1, B2 and B3 were infected with $10^{6} \mathrm{EID}_{50}$ pi/China/SH/2013/167. Positive-control group (PC) birds were intramuscularly injected with $10^{6}$ EID $_{50}$ F48E8; and negativecontrol group (NC) birds were inoculated with sterile PBS (pH 7.2). IV, intravenous injection; IM, intramuscular injection; IN, intranasal infection; 10 , intraocular infection

\begin{tabular}{|c|c|c|c|c|c|c|c|c|c|}
\hline \multicolumn{2}{|c|}{ Group } & $\mathrm{A} 1$ & $\mathrm{~A} 2$ & A3 & B1 & B2 & B3 & $P C$ & $\mathrm{NC}$ \\
\hline \multicolumn{2}{|l|}{ dpi } & IV & $\mathrm{IM}$ & $|N \&| O$ & IV & $\mathrm{IM}$ & $|\mathrm{N} \&| O$ & $\mathrm{IM}$ & IM \\
\hline & Orophary & $0 / 7$ & $0 / 7$ & $2 / 7$ & $2 / 7$ & $1 / 7$ & $2 / 7$ & $2 / 6$ & /7 \\
\hline & Cloacal & $0 / 7$ & $0 / 7$ & $0 / 7$ & $1 / 7$ & $0 / 7$ & $0 / 7$ & $0 / 6$ & $0 / 7$ \\
\hline & Orop & $3 / 7$ & $1 / 7$ & 2 & $3 / 7$ & $6 / 7$ & $1 /$ & 16 & D/7 \\
\hline & Cloaca & $0 / 7$ & $0 / 7$ & $0 / 7$ & $1 / 7$ & $0 / 7$ & $1 / 7$ & $2 / 6$ & $0 / 7$ \\
\hline \multirow[t]{2}{*}{10} & Oroph & $3 / 7$ & $4 / 7$ & $0 / 7$ & 17 & $3 / 7$ & $1 / 1$ & 14 & $0 / 7$ \\
\hline & Cloacal & $7 / 7$ & $6 / 7$ & $1 / 7$ & $6 / 7$ & $7 / 7$ & $1 / 7$ & $1 / 4$ & $0 / 7$ \\
\hline \multirow[t]{2}{*}{14} & Orol & $0 / 7$ & $0 / 7$ & $0 / 7$ & $1 / 7$ & $0 / 7$ & 0/ & /4 & $0 / 7$ \\
\hline & Cloaca & $1 / 7$ & $1 / 7$ & $0 / 7$ & $2 / 7$ & $1 / 7$ & $1 / 7$ & $1 / 4$ & $0 / 7$ \\
\hline \multirow[t]{2}{*}{21} & Orop & $0 / 7$ & $0 / 7$ & $1 / 7$ & 7 & $0 / 7$ & 0/ & $/ 4$ & //7 \\
\hline & Cloacal & $1 / 7$ & $0 / 7$ & $0 / 7$ & $0 / 7$ & $0 / 7$ & $0 / 7$ & $0 / 4$ & $0 / 7$ \\
\hline \multirow[t]{2}{*}{28} & Orop & $0 / 7$ & $0 / 7$ & $0 / 7$ & $0 / 7$ & $0 / 7$ & o/ & $0 / 4$ & $0 / 7$ \\
\hline & Cloacal & $0 / 7$ & $0 / 7$ & $0 / 7$ & $0 / 7$ & $0 / 7$ & $0 / 7$ & $0 / 4$ & $0 / 7$ \\
\hline \multirow[t]{2}{*}{35} & Orophary & $0 / 7$ & $0 / 7$ & $0 / 7$ & $0 / 7$ & $0 / 7$ & $0 / 7$ & 4 & $0 / 7$ \\
\hline & Cloacal & $0 / 7$ & $0 / 7$ & $0 / 7$ & $0 / 7$ & $0 / 7$ & $0 / 7$ & $0 / 4$ & $0 / 7$ \\
\hline \multirow[t]{2}{*}{42} & Oropharyngeal & $0 / 7$ & $0 / 7$ & $0 / 7$ & $0 / 7$ & $0 / 7$ & $0 / 7$ & $0 / 4$ & $0 / 7$ \\
\hline & Cloacal & $0 / 7$ & $0 / 7$ & $0 / 7$ & $0 / 7$ & $0 / 7$ & $0 / 7$ & $0 / 4$ & $0 / 7$ \\
\hline
\end{tabular}

distinct provinces in China (Fig. 2, Additional file 3: Table S3 and Additional file 4: Table S4). In a Chinese outbreak around 2000, subgenotype VIb, VIf and VIg [19] were all identified from pigeons, chickens and other fowls, whereas in the last decade, little VIf and VIg outbreaks have been reported [21]. Subgenotype VIb NDV is the most common in pigeons worldwide in the past two decades, and isolation of other subgenotypes, such as VIa, VId, VIf and VIg is rarely reported. Our four PPMV-1 isolates, ND132, ND163, ND167 and ND168, had high homology to each other but not to Chinese VIb isolates (representative strain YZ9712) from 10 years ago.

In this study, we used the Aldous method to further classify genotype VI genotype strains, which was based on 374 nucleotides in F protein of PPMV-1 isolated from Asia, Europe and America from 1978 to 2002 [34]. Based on this typing method, subgenotype VIb was divided into six clades: $a, b, c, d$, e and f. The first three were termed 4bi and the others 4bii. Two groups of VIb PPMV-1 were frequently isolated in China from 1998 until 2013. These groups are 4 bii $\mathrm{f}$ clade and 4 bii $\mathrm{d}$ clade. Isolates in clade $\mathrm{d}$ span three continents from 1983 to 2001. Isolates in this clade have been inferred to 
originate from two isolates in 1995, one from a budgerigar in Turkey, the other from a pigeon in Germany [34]. In this clade, Chinese, European and American isolates clustered on a separate branch from Middle Eastern isolates. Chinese PPMV-1 in this clade were isolated one or two decades ago, with the exception of $\mathrm{pi} / \mathrm{CH} /$ SD2012, which was isolated in the Shandong province of China in 2012 [37]. These results suggested that viruses in the 4 bii $\mathrm{d}$ clade were not widespread in China in recent decade.

Our four PPMV-1 isolates and most strains isolated from China in recent decade were highly homologous to Belgian isolates from 1998 to 2011, all of which clustered in 4bii f. This clade contained European and Middle Eastern viruses isolated from pigeons between 1998 and 2011. Based on the phylogenetic analysis and isolation date, 4 bii $\mathrm{d}$ was the predominant clade in China 20 years ago. The clade $4 \mathrm{bii} \mathrm{f}$ viruses began to emerge in the late 2000s, when the clade 4 bii d viruses began to decline.

PPMV-1 isolates in 4bii $\mathrm{f}$ mainly diverged into three branches, termed Belgium/98-like, P4-like and Belgium/ 11-like in this study. All three branches originated from PPMV-1 strains such as PPMV-1/Belgium/98-231/1998, PPMV-1/Belgium/98-238/1998 and PPMV-1/Belgium/ 98-248/1998 isolated in Belgium around 1998. ND132, ND163, ND167 and ND168 were classified into different branches of 4bii f. ND132 clustered with P4 and W4 on a separate branch of the 4bii f clade. Both P4 and W4 were isolated from wild birds in Guangdong province, south of China; P4 was from a wild pigeon in 2003 and W4 from a white-breasted water hen in 2005. Molecular dating based on different genes suggests that these viruses diverged from a common ancestor around 1999 [39]. Viruses belonging to this branch were continually isolated in distinct provinces of China from 2003 until 2013, suggesting P4-like PPMV-1 has long been circulating throughout China.

The genomic sequences of three Shanghai NDV isolates, ND163, ND167 and ND168, showed the highest homology to PPMV-1/Belgium/11-08304/2011 (99.02\%) [42]. The nucleotide and amino acid identities of six viral proteins were even higher, at $99.04-100 \%$. All other isolates in this branch were isolated in China since 2011. This result suggested that the viruses diverged from a common ancestor around 2011 and presumably were transmitted from Europe. In summary, our four isolates represented two groups of PPMV-1 prevailing in China in recent years. The P4-like group emerged around 1998 and the Belgium/11-like group around 2011.

Our cross- $\mathrm{HI}$ and cross- $\mathrm{VN}$ results showed antigenicity differences between the commonly used vaccine LaSota and current PPMV-1 strains in China, especially ND167, which is in a clade of the Belgium/11-like group. The $R$ values of NDV167 compared with LaSota were 0.287 in cross- $\mathrm{HI}$ assays and 0.208 in cross- $\mathrm{VN}$ assays, suggesting that PPMV-1 strains prevailing in China were antigenically changing. The specific amino acid substitutions in the $\mathrm{F}$ and HN proteins of NDV167 may have led to major antigenicity differences, such as M14 T, P28S, V179I, A203S, V506I in F protein and I59V, A66V, L74I, T232 N, S432H, A497T, D569E in HN protein. Recent Chinese and European isolates of PPMV-1 diverged from a common origin and kept changing, probably due to immune pressure of the live NDV vaccines such as LaSota. These mutations led to antigenic variation and will probably result in the inefficiency of the vaccine in the foreseeable future.

Phylogenetic analysis of the entire genome of four PPMV-1 isolates in this study showed that the viruses prevailing in China in recent years originated from Europe, and had high identity with Belgian isolates from 1998 to 2011. No virulence-related mutations were found in the six viral genes of the current Chinese isolates compared to the Belgian isolates. To determine the virulence of those viruses, we measured pathogenicity to pigeons of ND132 in the P4-like group and ND167 in the Belgium/11-like group.

All pigeons infected with ND132 and ND167 showed transient clinical signs but no mortality when pigeons were infected with PPMV-1 via oral administration, intramuscular injection, or intravenous injection. In contrast, the chicken-origin virulent NDV strain F48E8 caused $100 \%$ morbidity; three pigeons died and four survived. The genotype VIb PPMV-1 appeared to be less pathogenic to pigeons than the chicken-origin strain F48E8 did, which was consistent with the ICPI values. In previous studies, the pathogenicity of VIb to chickens was determined to be mesogenic $[37,38]$. Thus, the 4bii PPMV-1 strains used in this study displayed the same pathogenicity as reported for European isolates [43-46]; pigeons seemed to be resistant to those viruses. In other words, no definitive evidence confirmed a marked increase in the pathogenicity of recent Chinese isolates to pigeons. The high mortality clinically observed in China may not be caused simply by genetic variation of endemic strains; the influence of the pigeon lineage, co-infection with other pathogenic microorganisms, feeding environment, and even local climate need to be reconsidered.

A notable problem is viral shedding from infected pigeons. Our results showed that infected pigeons continued to shed, even at 3 weeks after infection, suggesting healthy pigeons could be PPMV-1 carriers. Based on epidemiological surveys, genotype VIb strains were identified from healthy-looking pigeons and doves. All isolates had a virulence motif of ${ }^{112} \mathrm{RRQKRF}^{117}$ in the $\mathrm{F}$ protein $[3,47]$. The virulent isolates from symptomless pigeons from 2011 to 2013 in live poultry markets clustered in the 4bii f clade [3] and were highly homologous to our isolates. We propose that recent 4 bii velogenic 
PPMV-1 isolates tended to develop a symbiotic relationship with pigeons so that infected pigeons showed no symptoms, became healthy carriers and shed occasionally. Previous studies showed that the same PPMV-1 strains were equally pathogenic to chickens and pigeons $[48,49]$. The disease in pigeons occurs because of spread from diseased chicken flocks and from domesticated or feral pigeons to poultry [50]. Pigeon-origin subtype VIb viruses are widely considered to be responsible for the third pandemic of the 1980s. As reported in this study, current PPMV-1 isolates are gradually changing and giving rise to antigenic differences from vaccine strain LaSota, suggesting that PPMV-1 will be an imminent threat to NDV control worldwide.

\section{Conclusion}

In this study, the full-length genomes of four virulent PPMV-1 strains, ND132, ND163, ND167 and ND168, were sequenced and subjected to phylogenetic analysis. Phylogenetic analysis revealed that the four PPMV-1 isolates were highly homologous to Belgian isolates from 1998 to 2011, as most of the recent isolates in China did, which suggested that the PPMV-1 strains prevailing in China in the last decade diverged from a common ancestor and was presumably transmitted from Europe. Several mutations were identified in the surface glycoproteins $\mathrm{F}$ and $\mathrm{HN}$, which probably gave rise to antigenicity differences of PPMV-1 strains isolated in 2013 from LaSota vaccine strain. In this study, PPMV-1 did not cause high mortality in experimental pigeons, however, infected pigeons were exhibiting for viral shedding for3 weeks after infection, suggesting PPMV-1 is a potential threat to NDV control worldwide.

\section{Additional files}

Additional file 1: Table S1. Primers used in this study to generate overlapping PCR fragments from the genome of pigeon-origin NDV isolates. (DOCX $16 \mathrm{~kb}$ )

Additional file 2: Table S2. Reference NDV strains in this study. (DOCX $52 \mathrm{~kb})$

Additional file 3: Table S3. Gene homology of NDV132 to other PPMV-1 strains (DOCX $18 \mathrm{~kb}$ )

Additional file 4: Table S4. Gene homology of NDV167 to other genotype VI NDV strains. (DOCX $17 \mathrm{~kb}$ )

\footnotetext{
Abbreviations

aa: Amino acid; APMV-1: Avian paramyxovirus-1; CAAS: Chinese Academy of Agricultural Science; dpi: Day post infection; EID $_{50}$ : 50\% embryo infectious dose; F: Fusion protein; HI: Hemagglutination inhibition; HN: Hemagglutininneuraminidase; ICPI: Intracerebral pathogenicity index; L: Large protein; M: Matrix protein; MDT: Mean death time; ND: Newcastle disease; NDV: Newcastle disease virus; NP: Nucleoprotein; nt: Nucleotides; P: Phosphoprotein; PBS: Phosphatebuffered saline; PCR: Polymerase chain reaction; PPMV-1: Pigeon paramyxovirus type 1; SD: Standard deviation; VN: Virus neutralization
}

\section{Funding}

This work was funded by the National Key Research and Development Program of China (2016YFD0501603) and Chinese Special Fund for Agro-scientific Research in the Public Interest (201303033). None of the funding sources had any role in study design, interpretation of results, or decision to publish.

\section{Availability of data and materials}

All data and materials described in the manuscript are available in the Additional files 1, 2, 3, 4

\section{Authors' contributions}

Conceived and designed the experiments: $C D$ and $X Q$. Performed the experiments: SL, TR and YZ. Analyzed the data: $X Q, C M, C S, Z D, L X$ and $Y S$. Contributed reagents/materials/analysis tools: LT, SX, LX and YL. Wrote the paper: XQ, SY, CM and CD. All authors read and approved the final manuscript.

\section{Ethics approval}

This study was carried out in strict accordance with the recommendations in the Guide for the Care and Use of Laboratory Animals of Shanghai Veterinary Research Institute (SHVRI), the Chinese Academy of Agricultural Sciences (CAAS). The protocols were approved by the Institutional Animal Care and Use Committee (IACUC) of SHVRI, CAAS.

\section{Consent for publication}

All the authors consent to publish.

\section{Competing interests}

The authors declare that they have no competing interests.

\section{Publisher's Note}

Springer Nature remains neutral with regard to jurisdictional claims in published maps and institutional affiliations.

\section{Author details}

${ }^{1}$ Shanghai Veterinary Research Institute, Chinese Academy of Agricultural Sciences, Shanghai 200241, People's Republic of China. ${ }^{2}$ Key Laboratory of Animal Infectious Diseases, Yangzhou University, Yangzhou, Jiangsu, China. ${ }^{3}$ Jiangsu Co-innovation Center for Prevention and Control of Important Animal Infectious Diseases and Zoonoses, Yangzhou, Jiangsu, China. ${ }^{4}$ Laboratory of Infectious Diseases, College of Veterinary Medicine, Jilin University, Changchun, Jilin, China.

Received: 3 May 2017 Accepted: 22 September 2017

Published online: 29 September 2017

\section{References}

1. Guo H, Liu X, Xu Y, Han Z, Shao Y, Kong X, Liu S. A comparative study of pigeons and chickens experimentally infected with PPMV-1 to determine antigenic relationships between PPMV-1 and NDV strains. Vet Microbiol. 2014;168:88-97.

2. Zhao B, Fu Y, Fan J, Xu B, Bu Z, Gao M, Chen W, Sun X. Development of Bivalent Inactivated Oil-emulsion Vaccine against Pigeon Paramyxovirus Disease. Jiangsu Journal of Agricultural Sciences. 2010;26:1293-7.

3. Wang J, Liu H, Liu W, Zheng D, Zhao Y, Li Y, Wang Y, Ge S, Lv Y, Zuo Y, et al. Genomic Characterizations of Six Pigeon Paramyxovirus Type 1 Viruses Isolated from Live Bird Markets in China during 2011 to 2013. PLoS One. 2015:10:e0124261.

4. de Leeuw O, Peeters B. Complete nucleotide sequence of Newcastle disease virus: evidence for the existence of a new genus within the subfamily Paramyxovirinae. J Gen Virol. 1999;80(Pt 1):131-6.

5. Mayo MA. A summary of taxonomic changes recently approved by ICTV. Arch Virol. 2002;147:1655-63.

6. Millar NS, Chambers P, Emmerson PT. Nucleotide sequence of the fusion and haemagglutinin-neuraminidase glycoprotein genes of Newcastle disease virus, strain Ulster: molecular basis for variations in pathogenicity between strains. J Gen Virol. 1988:69(Pt 3):613-20.

7. Samson AC, Levesley I, Russell PH. The 36K polypeptide synthesized in Newcastle disease virus-infected cells possesses properties predicted for the hypothesized 'V' protein. J Gen Virol. 1991;72(Pt 7):1709-13. 
8. Steward M, Vipond IB, Millar NS, Emmerson PT. RNA editing in Newcastle disease virus. J Gen Virol. 1993;74(Pt 12):2539-47.

9. Gould AR, Hansson E, Selleck K, Kattenbelt JA, Mackenzie M, Della-Porta AJ. Newcastle disease virus fusion and haemagglutinin-neuraminidase gene motifs as markers for viral lineage. Avian Pathol. 2003;32:361-73.

10. Czegledi A, Ujvari D, Somogyi E, Wehmann E, Werner O, Lomniczi B. Third genome size category of avian paramyxovirus serotype 1 (Newcastle disease virus) and evolutionary implications. Virus Res. 2006;120:36-48,

11. Alexander DJ, Campbell G, Manvell RJ, Collins MS, Parsons G, McNulty MS. Characterisation of an antigenically unusual virus responsible for two outbreaks of Newcastle disease in the Republic of Ireland in 1990. Vet Rec. 1992;130:65-8.

12. Mia Kim L, King DJ, Suarez DL, Wong CW, Afonso CL. Characterization of class I Newcastle disease virus isolates from Hong Kong live bird markets and detection using real-time reverse transcription-PCR. J Clin Microbiol. 2007:45:1310-4.

13. Bjarnadottir H, Gudmundsson B, Gudnason J, Jonsson JJ. Encapsidation determinants located downstream of the major splice donor in the maedivisna virus leader region. J Virol. 2006;80:11743-55.

14. Liu X, Wang X, Wu S, Hu S, Peng Y, Xue F. Surveillance for avirulent Newcastle disease viruses in domestic ducks (Anas platyrhynchos and Cairina moschata) at live bird markets in Eastern China and characterization of the viruses isolated. Avian Pathol. 2009;38:377-91.

15. Diel DG, da Silva LH, Liu H, Wang Z, Miller PJ, Afonso CL. Genetic diversity of avian paramyxovirus type 1: Proposal for a unified nomenclature and classification system of Newcastle disease virus genotypes. Infect Genet Evol. 2012;12:1770-9.

16. Huang Y, Wan HQ, Liu HQ, Wu YT, Liu XF. Genomic sequence of an isolate of Newcastle disease virus isolated from an outbreak in geese: a novel six nucleotide insertion in the non-coding region of the nucleoprotein gene. Brief Report. Arch Virol. 2004;149:1445-57.

17. Seal BS, Wise MG, Pedersen JC, Senne DA, Alvarez R, Scott MS, King DJ, Yu Q, Kapczynski DR. Genomic sequences of low-virulence avian paramyxovirus-1 (Newcastle disease virus) isolates obtained from live-bird markets in North America not related to commonly utilized commercial vaccine strains. Vet Microbiol. 2005;106:7-16.

18. Ujvari D, Wehmann E, Herczeg J, Lomniczi B. Identification and subgrouping of pigeon type Newcastle disease virus strains by restriction enzyme cleavage site analysis. J Virol Methods. 2006;131:115-21.

19. Liu XF, Wan HQ, Ni XX, Wu YT, Liu WB. Pathotypical and genotypical characterization of strains of Newcastle disease virus isolated from outbreaks in chicken and goose flocks in some regions of China during 1985-2001. Arch Virol. 2003:148:1387-403.

20. Liu H, Wang Y, Yan W, Zhu G, Chen F. Investigation on the Molecular Epidemiology of Newcastle Disease Virus in China. Chinese Journal of Veterinary Science. 2003:218-21.

21. Chen $S$, Hao H, Liu Q, Wang R, Zhang P, Wang X, Du E, Yang Z. Phylogenetic and pathogenic analyses of two virulent Newcastle disease viruses isolated from Crested Ibis (Nipponia nippon) in China. Virus Genes. 2013:46:447-53.

22. Alexander DJ. Newcastle disease in the European Union 2000 to 2009. Avian Pathol. 2011;40:547-58

23. de Leeuw OS, Koch G, Hartog L, Ravenshorst N, Peeters BP. Virulence of Newcastle disease virus is determined by the cleavage site of the fusion protein and by both the stem region and globular head of the haemagglutinin-neuraminidase protein. J Gen Virol. 2005:86:1759-69.

24. Collins MS, Bashiruddin JB, Alexander DJ. Deduced amino acid sequences at the fusion protein cleavage site of Newcastle disease viruses showing variation in antigenicity and pathogenicity. Arch Virol. 1993;128:363-70.

25. Sakaguchi T, Matsuda Y, Kiyokage R, Kawahara N, Kiyotani K, Katunuma N, Nagai Y, Yoshida T. Identification of endoprotease activity in the trans Golgi membranes of rat liver cells that specifically processes in vitro the fusion glycoprotein precursor of virulent Newcastle disease virus. Virology. 1991; 184:504-12.

26. Kawahara N, Yang XZ, Sakaguchi T, Kiyotani K, Nagai Y, Yoshida T. Distribution and substrate specificity of intracellular proteolytic processing enzyme(s) for paramyxovirus fusion glycoproteins. J Gen Virol. 1992;73(Pt 3):583-90.

27. Alexander DJ. Newcastle disease. In: World Organisation for Animal Health (OIE) Manual of Diagnostic Tests and Vaccines for Terrestrial Animals. 6th ed. Paris: OlE; 2008. p. 576-89.

28. Hutchison DC. Paramyxovirus infection in pigeons. Vet Rec. 1984;115:335.

29. Marlier D, Vindevogel H. Viral infections in pigeons. Vet J. 2006;172:40-51.
30. Gough RE, Alexander DJ, Collins MS, Lister SA, Cox WJ. Routine virus isolation or detection in the diagnosis of diseases in birds. Avian Pathol. 1988;17:893-907.

31. Qiu X, Sun Q, Wu S, Dong L, Hu S, Meng C, Wu Y, Liu X. Entire genome sequence analysis of genotype IX Newcastle disease viruses reveals their early-genotype phylogenetic position and recent-genotype genome size. Virol J. 2011;8:117.

32. Qiu X, Sun Q, Wang W, Dong L, Wu S, Hu S, Wu Y, Liu X. Analysis of leader and trailer sequence of genotype III, Vlb and VIId Newcastle disease virus determined by modified rapid amplification of CDNA ends (RACE) strategy. Wei Sheng Wu Xue Bao. 2009:49:965-71.

33. Kumar S, Stecher G, Tamura K. MEGA7: Molecular Evolutionary Genetics Analysis Version 7.0 for Bigger Datasets. Mol Biol Evol. 2016;33:1870-74.

34. Aldous EW, Fuller CM, Mynn JK, Alexander DJ. A molecular epidemiological investigation of isolates of the variant avian paramyxovirus type 1 virus (PPMV-1) responsible for the 1978 to present panzootic in pigeons. Avian Pathol. 2004;33:258-69.

35. Archetti I, Horsfall FL Jr. Persistent antigenic variation of influenza A viruses after incomplete neutralization in ovo with heterologous immune serum. J Exp Med. 1950;92:441-62.

36. Freick M, Muller H, Raue R. Rapid detection of pigeon herpesvirus, fowl adenovirus and pigeon circovirus in young racing pigeons by multiplex PCR. J Virol Methods. 2008;148:226-31.

37. Awu A, Shao MY, Liu MM, Hu YX, Qin ZM, Tian FL, Zhang GZ. Characterization of two pigeon paramyxovirus type 1 isolates in China. Avian Pathol. 2015:44:204-11.

38. Guo H, Liu X, Han Z, Shao Y, Chen J, Zhao S, Kong X, Liu S. Phylogenetic analysis and comparison of eight strains of pigeon paramyxovirus type 1 (PPMV-1) isolated in China between 2010 and 2012. Arch Virol. 2013;158: 1121-31.

39. Cai S, Li J, Wong MT, Jiao P, Fan H, Liu D, Liao M, Jiang J, Shi M, Lam TT, et al. Genetic characterization and evolutionary analysis of 4 Newcastle disease virus isolate full genomes from waterbirds in South China during 2003-2007. Vet Microbiol. 2011;152:46-54.

40. Reed $\mathrm{L}$, Muench $\mathrm{H}$. A simple method of estimating fifty percent endpoints. Am J Hyg. 1938;27:493-7.

41. Li S, Qiu X, Liu K, Zhou J, Liu J, Ju H, Tan L, Sun Y, Song C, Liu P, Ding C Isolation, Identification and Bioinformatics Analysis of Six Newcastle Disease Viruses of Pigeon Origin. Chinese Journal of Animal Infectious Diseases. 2014;22:1-9.

42. Van Borm S, Rosseel T, Steensels M, van den Berg T, Lambrecht B. What's in a strain? Viral metagenomics identifies genetic variation and contaminating circoviruses in laboratory isolates of pigeon paramyxovirus type 1. Virus Res. 2013:171:186-93.

43. Biancifiori F, Fioroni A. An occurrence of Newcastle disease in pigeons: virological and serological studies on the isolates. Comp Immunol Microbiol Infect Dis. 1983;6:247-52.

44. Alexander DJ, Parsons G. Avian paramyxovirus type 1 infections of racing pigeons: 2 pathogenicity experiments in pigeons and chickens. Vet Rec. 1984;114:466-9.

45. Kapczynski DR, Wise MG, King DJ. Susceptibility and protection of naive and vaccinated racing pigeons (Columbia livia) against exotic Newcastle disease virus from the California 2002-2003 outbreak. Avian Dis. 2006;50:336-41.

46. de Oliveira Torres Carrasco A, Seki MC, de Freitas RT, Paulillo AC, Pinto AA. Experimental infection of Newcastle disease virus in pigeons (Columba livia): humoral antibody response, contact transmission and viral genome shedding. Vet Microbiol. 2008;129:89-96.

47. Kim LM, King DJ, Guzman H, Tesh RB, Travassos da Rosa AP, Bueno R Jr, Dennett JA, Afonso CL. Biological and phylogenetic characterization of pigeon paramyxovirus serotype 1 circulating in wild North American pigeons and doves. J Clin Microbiol. 2008:46:3303-10.

48. Pan YF, Tan YX, Wang M, Zhang J, Zhang B, Yang C, Ding ZW, Dong LW, Wang HY. Signal regulatory protein alpha is associated with tumor-polarized macrophages phenotype switch and plays a pivotal role in tumor progression. Hepatology. 2013;58:680-91.

49. Wu X, Guo W, Wu L, Gu Y, Gu L, Xu S, Wu X, Shen Y, Ke Y, Tan R, et al. Selective sequestration of STAT1 in the cytoplasm via phosphorylated SHP-2 ameliorates murine experimental colitis. J Immunol. 2012:189:3497-507.

50. Alexander DJ, Parsons G. Pathogenicity for chickens of avian paramyxovirus type 1 isolates obtained from pigeons in Great Britain during 1983-85. Avian Pathol. 1986;15:487-93. 